\title{
QBO Influence on MJO Amplitude over the Maritime Continent: Physical Mechanisms and Seasonality
}

\author{
CASEy R. DENSMORE \\ Oceanography Department, U.S. Naval Academy, Annapolis, Maryland, and \\ MIT-WHOI Joint Program in Oceanography, Woods Hole, Massachusetts \\ ELIZABETH R. SANABIA AND BRADFORD S. BARRETT \\ Oceanography Department, U.S. Naval Academy, Annapolis, Maryland
}

(Manuscript received 3 May 2018, in final form 15 November 2018)

\begin{abstract}
The quasi-biennial oscillation (QBO) is stratified by stratospheric zonal wind direction and height into four phase pairs [easterly midstratospheric winds (QBOEM), easterly lower-stratospheric winds, westerly midstratospheric winds (QBOWM), and westerly lower-stratospheric winds] using an empirical orthogonal function analysis of daily stratospheric (100-10 hPa) zonal wind data during 1980-2017. Madden-Julian oscillation (MJO) events in which the MJO convective envelope moved eastward across the Maritime Continent (MC) during 1980-2017 are identified using the Real-time Multivariate MJO (RMM) index and the outgoing longwave radiation (OLR) MJO index (OMI). Comparison of RMM amplitudes by the QBO phase pair over the MC (RMM phases 4 and 5) reveals that boreal winter MJO events have the strongest amplitudes during QBOEM and the weakest amplitudes during QBOWM, which is consistent with QBO-driven differences in upper-tropospheric lower-stratospheric (UTLS) static stability. Additionally, boreal winter RMM events over the MC strengthen during QBOEM and weaken during QBOWM. In the OMI, those amplitude changes generally shift eastward to the eastern MC and western Pacific Ocean, which may result from differences in RMM and OMI index methodologies. During boreal summer, as the northeastwardpropagating boreal summer intraseasonal oscillation (BSISO) becomes the dominant mode of intraseasonal variability, these relationships are reversed. Zonal differences in UTLS stability anomalies are consistent with amplitude changes of eastward-propagating MJO events across the MC during boreal winter, and meridional stability differences are consistent with amplitude changes of northeastward-propagating BSISO events during boreal summer. Results remain consistent when stratifying by neutral ENSO phase.
\end{abstract}

\section{Introduction}

Several recent studies have analyzed relationships between the quasi-biennial oscillation (QBO; Lindzen and Holton 1968; Baldwin et al. 2001) and amplitudes of the Madden-Julian oscillation (MJO; Madden and Julian 1971, 1972) in boreal (and extended boreal) winter (e.g., Liu et al. 2014; Yoo and Son 2016; Marshall et al. 2017; Nishimoto and Yoden 2017; Son et al. 2017; Zhang and Zhang 2018). The primary findings of those studies are that during boreal winter, MJO amplitudes are stronger when 50-hPa zonal winds are easterly, and MJO amplitudes are weaker when $50-\mathrm{hPa}$ winds are westerly. Several studies (e.g., Yoo and Son 2016; Son

Corresponding author: Casey R. Densmore, cdensmore101@ gmail.com et al. 2017; Nishimoto and Yoden 2017) relate wind conditions associated with changes in MJO amplitudes to $100-\mathrm{hPa}$ static stability differences. Increased MJO amplitudes are found to be associated with lower $100-\mathrm{hPa}$ static stabilities associated with QBO winds. Conversely, decreased MJO amplitudes are found to be associated with higher 100-hPa static stabilities associated with QBO winds. The connection between QBO conditions and static stability referenced in those studies is supported by Baldwin et al. (2001), who linked QBO-driven zonal wind shear to stratospheric temperature perturbations through thermal wind balance. During easterly conditions, zonal winds, which become more easterly with height, drive cold midstratospheric temperature perturbations, decreasing near-tropopause stability (Kedzierski et al. 2016) and strengthening deep convection (Collimore et al. 2003). Conversely, during 
westerly conditions, zonal winds, which become more westerly with height, drive warm midstratospheric temperature perturbations, increasing near-tropopause stability and weakening deep convection. Other mechanisms suggested to explain QBO effects on tropical MJO convection include differences in vertical shear of the zonal winds across the tropopause (Collimore et al. 2003) and differences in upper-tropospheric radiative processes associated with QBO-driven cirrus cloud formation or suppression (Yoo and Son 2016). Very recently, Zhang and Zhang (2018) noted that this result may be driven by more active MJO days and slower eastward propagation during easterly stratospheric winds, and not necessarily by stronger individual active $\mathrm{MJO}$ events, and concluded that the question of relationships between QBO and the MJO remains an active area of study.

Studies investigating the relationship between QBO and MJO tend to categorize the QBO using a zonal wind analysis at a fixed pressure level (e.g., $50 \mathrm{hPa}$; Liu et al. 2014; Yoo and Son 2016; Marshall et al. 2017; Son et al. 2017; Nishimoto and Yoden 2017; Hendon and Abhik 2018; Zhang and Zhang 2018; Lee and Klingaman 2018; Wang et al. 2018). While this method captures the directionality of stratospheric zonal winds during the QBO, it does not necessarily capture the vertical structure of zonal winds throughout the stratosphere. Because both easterly and westerly wind maxima descend through the stratosphere over time, limiting analyses to a single vertical level may limit insight into the QBO-MJO relationship. Furthermore, because the static stability of the upper troposphere and lower stratosphere depends strongly on change in the zonal wind with height over a layer (e.g., Baldwin et al. 2001), a method of identifying the QBO that examines zonal wind at more than one level may improve understanding of the QBO-MJO association. In addition, no known studies have found a QBO-MJO relationship beyond extended boreal winter (November-March) or considered potential relationships between QBO and the boreal summer intraseasonal oscillation (BSISO; Lawrence and Webster 2002). Therefore, a need exists to continue to investigate the QBO-MJO relationship, particularly using methods that identify the QBO at more than one vertical level and in different seasons.

A focal point for this analysis is the MJO transit over the Maritime Continent (MC). The barrier effect and unpredictability of MJO propagation across the MC have been the subject of numerous studies in recent years (e.g., Peatman et al. 2014; Hagos et al. 2016; Feng et al. 2015; Zhang and Ling 2017; DeMott et al. 2018). Primary findings of these studies have related active MJO eastward propagation across the MC to several physical mechanisms, among them more humid conditions in and east of the MJO active envelope (Feng et al. 2015), heavier precipitation over waters surrounding MC islands (Zhang and Ling 2017), and weakening of the diurnal precipitation cycle over the MC (Peatman et al. 2014; Hagos et al. 2016). However, possible impacts from the QBO on MJO propagation across the MC have also been studied recently by Zhang and Zhang (2018), who found that termination longitudes of convection within MJO events are affected by QBO polarity, and both MJO-associated and total precipitation response to QBO polarity is not zonally uniform. Studying the MJO and its eastward propagation over the $\mathrm{MC}$ is further complicated by interactions between the MJO and other atmospheric and oceanic oscillations, notably El Niño-Southern Oscillation (ENSO). Previous studies have shown that MJO activity is affected by ENSO (e.g., Tam and Lau 2005; McPhaden et al. 2006; Gushchina and Dewitte 2012; Feng et al. 2015), and, therefore, MJO interaction with ENSO should be considered when studying other oscillations, including the QBO.

This study extends understanding of the QBO-MJO relationship in several ways. First, the QBO is categorized using an empirical orthogonal function analysis [similar to Wallace et al. (1993) and Fraedrich et al. (1993)] that quantifies the full vertical structure of stratospheric winds. The relationships between QBO zonal wind shear, temperature perturbations, and static stability are examined in the context of this two-dimensional QBO phase space. Second, relationships between QBO phase and MJO amplitude across the MC are analyzed for boreal winter and are stratified by ENSO. Finally, the analysis is extended to all months to understand the potential seasonality of those relationships. The remainder of this article is organized as follows: data and methods are presented in section 2, results are presented in section 3, and discussion and conclusions are presented in section 4 .

\section{Data and methods}

\section{a. Identifying the MJO and BSISO}

MJO intensity and location were quantified first using the Wheeler and Hendon (2004, hereafter WH04) Realtime Multivariate MJO (RMM) index. This index is freely available for download from the Australian $\mathrm{Bu}$ reau of Meteorology (www.bom.gov.au/climate/mjo/). The WH04 RMM index uses an EOF analysis of lower$(850 \mathrm{hPa})$ and upper-level $(200 \mathrm{hPa})$ zonal winds, and outgoing longwave radiation (OLR) to identify primarily the strength and location of the enhanced convective envelope of the MJO (hereafter the active envelope). The RMM index is used widely in operational settings because of its real-time updates and simplicity of interpretation, but it has known 
shortcomings. Notably, higher-frequency synoptic variability can project onto the RMM index (Roundy et al. 2009), which may then indicate westward MJO propagation or other uncharacteristic features. In addition, the RMM index has been demonstrated to exhibit a bias toward zonal wind observations over OLR observations, meaning shifts in large-scale convection and precipitation associated with the MJO may not be projected well onto the index (Straub 2013). To account for those biases, MJO intensity and location were also quantified using another recently developed MJO index, the OLR MJO index (OMI; Kiladis et al. 2014), which is based on an EOF analysis of only bandpass-filtered OLR to project MJO strength and geographic position onto a phase space similar to the RMM. The OMI quantifies the MJO based on its convective anomalies, which can be an advantage over the RMM index. However, because of its focus on OLR, the OMI can miss MJO-driven circulation features. To account for these strengths and weaknesses, the MJO will be analyzed using both indices.

Several recent studies (e.g., Yoo and Son 2016; Zhang and Zhang 2018) have used both the RMM and OMI indices to quantify MJO events and their relationships with other modes of atmospheric variability. However, in boreal summer, global EOF-based MJO indices may inaccurately quantify location and strength of intraseasonal convection (Lee et al. 2013). This potential uncertainty is related to the development of the BSISO (Lawrence and Webster 2002), a near-equatorial, northwestward-tilted band of convection that propagates northeastward across the MC and southeastern Asia away from the equator at a phase speed similar to the MJO. To capture this equatorially asymmetric, northeastward-propagating convection, several additional indices have been developed (e.g., Kikuchi et al. 2012; Lee et al. 2013). To account for the abovementioned weaknesses in the RMM and OMI indices, and to account for the shift from MJO to BSISO in boreal summer, all three indices [RMM, OMI, and the Kikuchi et al. (2012) BSISO index] were used to identify both MJO events and MJO days throughout the year (and BSISO events and BSISO days during boreal summer) and then relate them to the QBO.

For all seasons from 1980 to 2017, 143 MJO events (spanning 2098 active MJO days as defined in section 2c) were identified that progressed through RMM phases 4 and 5, which approximately correspond to the active envelope crossing the MC (WH04) (Fig. 1). Over the same time period, $123 \mathrm{MJO}$ events that propagated across the MC (1639 active MJO days) were identified using the OMI. Finally, during boreal summer from 1980 to 2017, 45 BSISO events (466 active BSISO days) that progressed northeastward across the $\mathrm{MC}$ and southeastern Asia

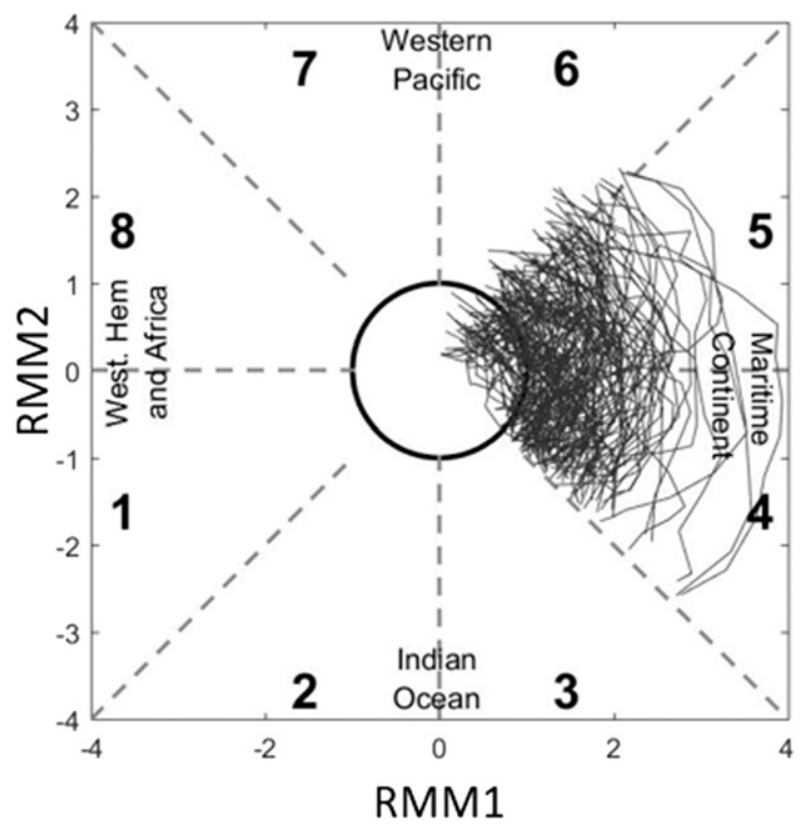

FIG. 1. Daily progression of 143 initially active MJO events (comprising 2098 MJO days) over the Maritime Continent through the Real-time Multivariate MJO (RMM) index phase space (RMM phases 4 and 5) from 1980 to 2017 for all months.

were identified using the BSISO index. To be considered an MJO event in this analysis, an event had to cross from phase 3 into phase 4 with an amplitude greater than or equal to 1.0 and had to demonstrate counterclockwise progression in its respective (RMM, OMI, or BSISO) phase space on at least $65 \%$ of the days it was in phases 4 and 5. This constraint was imposed to retain the greatest number of MJO events while excluding events that were stationary or moving substantially clockwise in their respective phase space (Jones et al. 2015; LaFleur et al. 2015). For the RMM index, mean changes in MJO event amplitude were calculated over the MC as follows:

$$
\Delta \mathrm{RMM}=\frac{\sum_{j=1}^{n} \operatorname{RMM}_{f}(j)-\operatorname{RMM}_{i}(j)}{n},
$$

where $\operatorname{RMM}_{i}(j)$ and $\operatorname{RMM}_{f}(j)$ are the RMM amplitudes for each MJO event at the entrance to phase 4 and exit from phase 5, respectively, and $n$ is the number of active MJO events that occurred during each QBO phase pair (defined in section 2b). This analysis of MJO amplitude was extended to OMI and BSISO index amplitudes in a similar manner.

\section{b. Identifying the $Q B O$}

The QBO was identified from 1980 to 2017 using an EOF analysis of daily stratospheric zonal wind anomalies, 

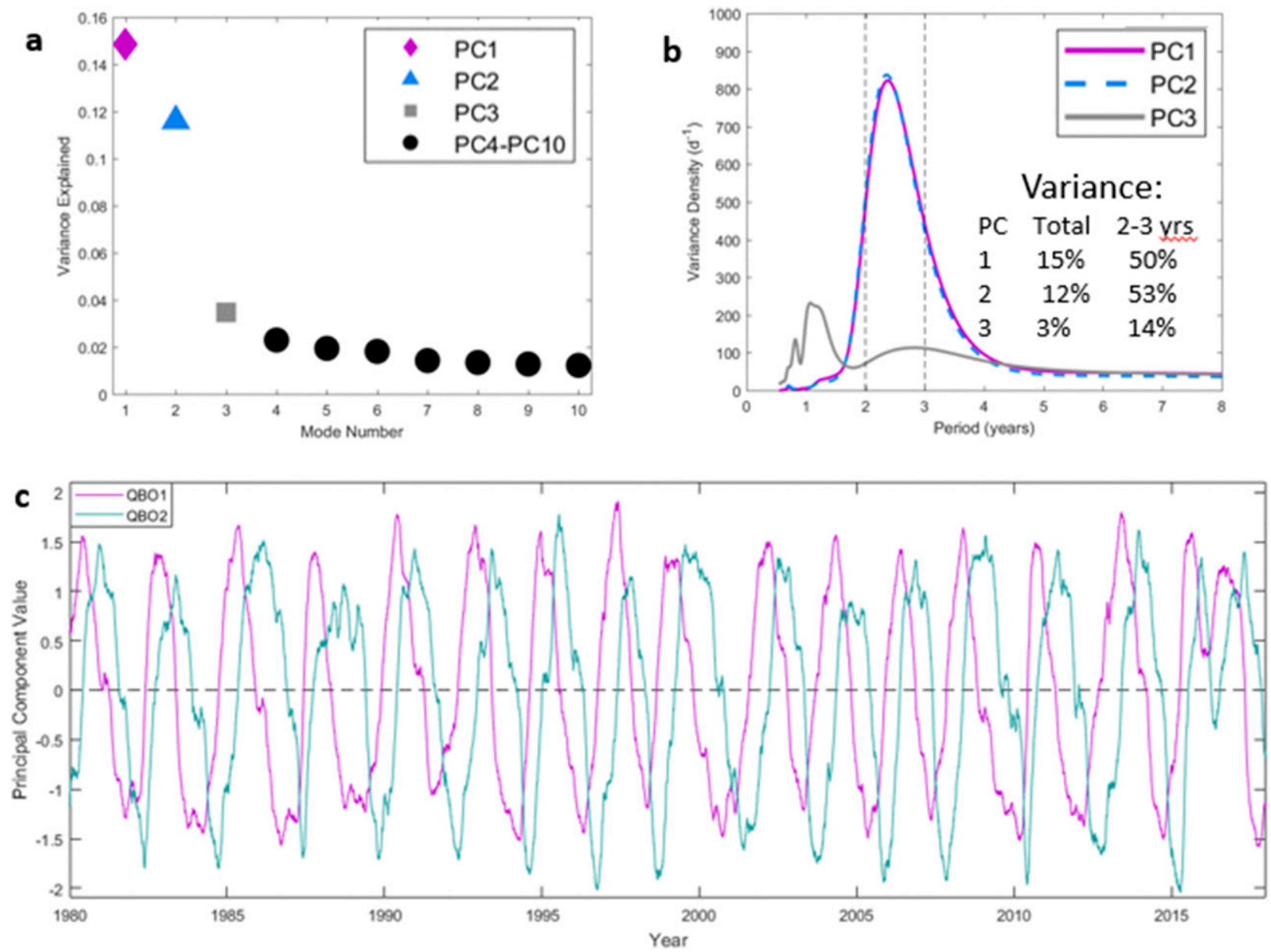

FIG. 2. (a) Total variance of stratospheric winds from 1980 to 2017 accounted for by the first 10 principal components of the EOF analysis, (b) variance density spectra of the first three principal components, and (c) daily time series of the first two principle components, normalized by their respective standard deviations (QBO1 and QBO2, respectively). Dashed vertical lines in (b) denote periods between 2 and 3 years.

averaged meridionally from $10^{\circ} \mathrm{S}$ to $10^{\circ} \mathrm{N}$ and bounded vertically by 100 and $10 \mathrm{hPa}$. Zonal wind data from the ECMWF interim reanalysis (ERA-Interim; Dee et al. 2011; www.ecmwf.int/en/forecasts/datasets/reanalysisdatasets/era-interim) were smoothed temporally using a 151-day running mean filter in order to remove synoptic to seasonal variability, following Wallace et al. (1993), and anomalies were calculated relative to a 31-day climatological (1980-2017) sliding mean (e.g., zonal wind anomalies on 16 January 1988 were calculated with respect to the 1-31 January 1980-2017 climatology). Variance explained by the first 10 principal components produced by this EOF analysis is presented in Fig. 2a. The first three principal components account for $15 \%$, $12 \%$, and $3 \%$, respectively, of the total variability in stratospheric zonal wind anomalies, while higher-order principal components account for decreased variability (Fig. 2a). The variability captured by the first two principal components is centered on the 2-3-yr time period
(Fig. 2b), which corresponds well to the mean periodicity of the QBO (Lindzen and Holton 1968; Baldwin et al. 2001). Specifically, $50 \%$ of the variability in the first principal component and $53 \%$ of the variability in the second principal component exist within this time window. Less than $15 \%$ of the variability in subsequent principal components falls within the QBO time scale, and therefore, those principal components will not be analyzed further. Daily time series of the first two principal components, normalized by their standard deviation and hereafter labeled QBO1 and QBO2, are presented in Fig. 2c. These principal components oscillate with a period of approximately 2.5 years, and demonstrate a phase shift of approximately $90^{\circ}$, reflecting their orthogonality. These first two principal components capture complementary variability of stratospheric winds, and together account for $27 \%$ of the 151-day low-pass-filtered daily stratospheric zonal wind variability. 

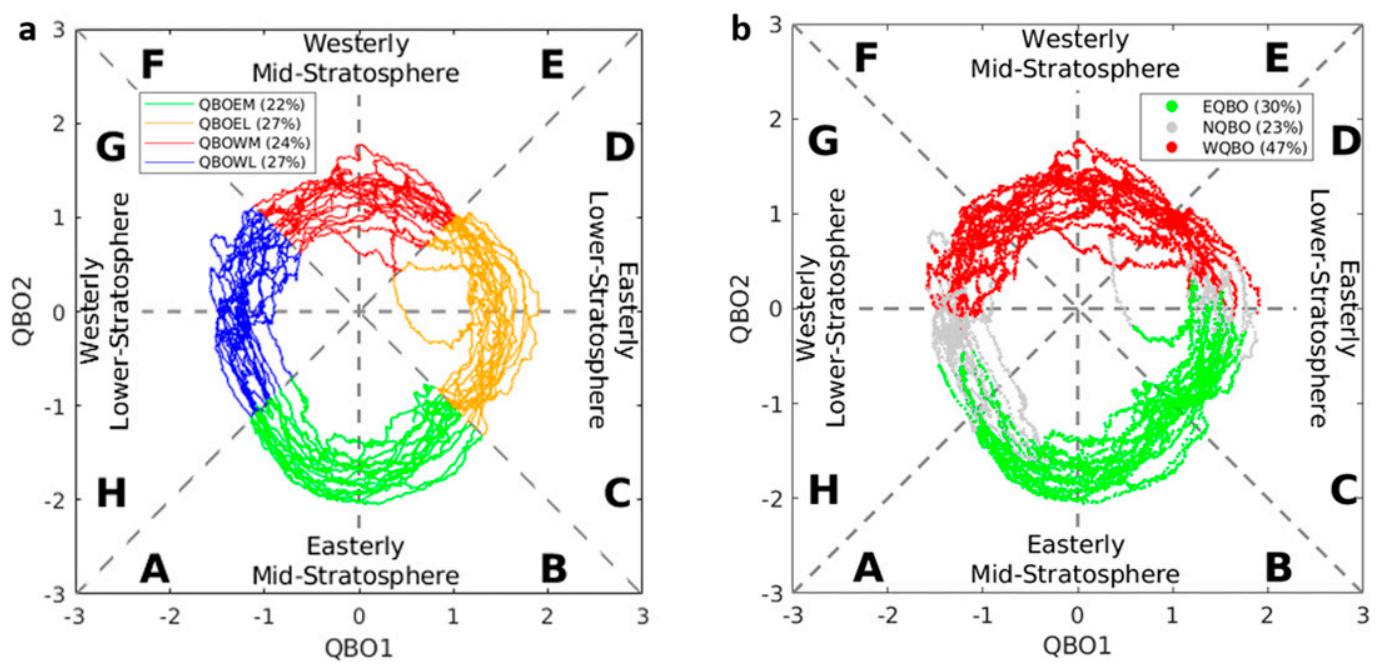

FIG. 3. (a) Phase space of QBO1 and QBO2 for all days, 1980-2017. Eight phases (separated by dashed lines) divide the QBO zonal winds by direction and altitude of the wind maxima. Distance from the center of the figure corresponds to zonal wind anomaly magnitude. Similar QBO wind profiles are binned into four phase-pair subsets, denoted by color as green [easterly midstratosphere (QBOEM)], orange [easterly lower stratosphere (QBOEL)], red [westerly midstratosphere (QBOWM)], and blue [westerly lower stratosphere (QBOWL)]. (b) The same QBO phase space, but color corresponds to the 50-hPa index classification (e.g., Yoo and Son 2016): easterly QBO (green), neutral QBO (gray), and westerly QBO (red). Percent of days in each (a) QBO EOF phase pair and (b) QBO 50-hPa phase are displayed in the legend in each panel.

The first two normalized principal components result in a QBO phase space (Fig. 3a) from which the QBO can be analyzed. The angle around the center of the diagram indicates the altitude and direction of the stratospheric zonal wind anomalies, the distance from the center corresponds to the magnitude of the anomalies, and QBO zonal wind conditions move counterclockwise around the phase space with time as the oscillation propagates downward through the stratosphere. Based on the angle in the phase space, the zonal wind profile generated by the QBO is divided into eight phases (labeled A-H in Fig. 3a and separated by dashed gray lines). These QBO phases are grouped in pairs (by dividing the phase space into four quadrants; hereafter "phase pairs") by common direction and approximate altitude of zonal wind maxima, which increases sample size and thus statistical significance. QBO phases A and B represent days with midstratospheric easterly winds (QBOEM; Figs. 3a and 4a), and QBO phases $\mathrm{C}$ and $\mathrm{D}$ represent days with lowerstratospheric easterly winds (QBOEL; Figs. 3a and $4 b)$. QBO phases $E$ and $F$ represent days with midstratospheric westerly winds (QBOWM; Figs. 3a and $4 \mathrm{~b}$ ), and QBO phases $\mathrm{G}$ and $\mathrm{H}$ represent days with lower-stratospheric westerly winds (QBOWL; Figs. 3a and $4 \mathrm{~d}$ ). Although there is a slight easterly component at $100 \mathrm{hPa}$ in the QBOWL zonal winds, net flow in the lower stratosphere is westerly.
This EOF analysis categorizes stratospheric zonal winds in a notably different manner than the $50-\mathrm{hPa}$ QBO index used in previous MJO-QBO studies (e.g., Yoo and Son 2016; Son et al. 2017; Zhang and Zhang 2018) (Fig. 3b). Zonal wind regimes categorized as easterly QBO with the $50-\mathrm{hPa}$ zonal wind index include a large number of days in both QBOEM and QBOEL $(61.6 \%$ and $34.8 \%$, respectively, with $3.6 \%$ of days in QBOWL), as confirmed with the EOF analysis here. Additionally, zonal wind regimes categorized as westerly QBO include a slight majority of days in QBOWM, with a large number of days in QBOWL and QBOEL $(50.7 \%$ in QBOWM, 28\% in QBOWL, and $21.3 \%$ in QBOEL). These differences in how stratospheric zonal wind conditions are binned suggest that there may be QBO-MJO connections that go undetected when categorizing QBO conditions with the $50-\mathrm{hPa}$ index, and they provide support for the EOF technique employed in this study.

To better understand potential physical mechanisms that may account for QBO-MJO and QBO-BSISO relationships, associations between QBO phase pair and atmospheric conditions such as zonal wind, vertical wind shear, and static stability are examined. Vertical profiles of each of these variables and parameters are calculated using ERA-Interim reanalysis data from 1980 to 2017. To create these vertical profiles, zonal means of the meridional average from $10^{\circ} \mathrm{S}$ to $10^{\circ} \mathrm{N}$ are calculated 

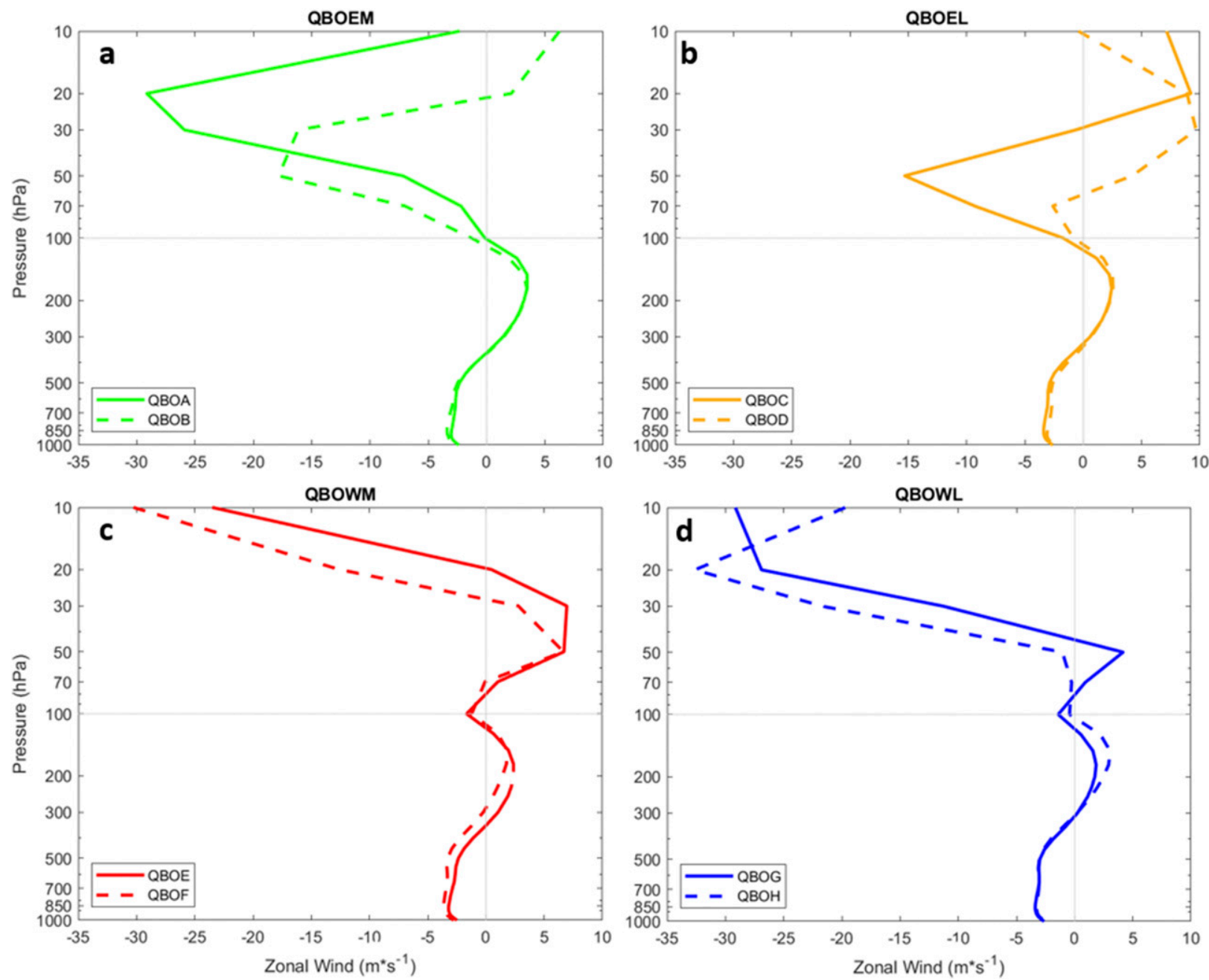

FIG. 4. Mean $\left(10^{\circ} \mathrm{S}-10^{\circ} \mathrm{N}, 0^{\circ}-360^{\circ}\right)$ zonal winds for all days, $1980-2017$ for each of the eight $\mathrm{QBO}$ phases defined in Fig. 3. Wind profiles are divided into four panels by zonal wind center height and direction.

at each level from 1000 and $10 \mathrm{hPa}$. All anomalies are calculated as deviations from the climatological mean (defined as a 31-day sliding window) from 1980 to 2017. Static stability $N^{2}$ is calculated as follows:

$$
N^{2}=\frac{g}{\theta} \frac{d \theta}{d z}
$$

where $g$ is the gravitational constant $\left(9.8 \mathrm{~m} \mathrm{~s}^{-2}\right), \theta$ is the potential temperature $(\mathrm{K})$, and $d \theta / d z$ is the change in potential temperature with height $\left(\mathrm{K} \mathrm{m}^{-1}\right.$; Stull 1995). To consider potential seasonality of the QBO-MJO relationship, MJO amplitude change and QBO effects on zonal wind shear and static stability were analyzed by seasonal subsets: boreal winter [December-JanuaryFebruary (DJF)], boreal spring [March-April-May (MAM)], boreal summer [June-July-August (JJA)], and boreal autumn [September-October-November (SON)].

\section{c. Connecting the $Q B O$ with the MJO and BSISO}

The geographic region of interest in this analysis is the $\mathrm{MC}$ (MJO phases 4 and 5). QBO-MJO relationships are evaluated based on QBO conditions present at the start of an MJO event (entrance to phase 4). There are a few occasions (6 of 139 in the RMM index and 5 of 123 in the OMI) when the QBO phase pair shifts (i.e., from QBOEM to QBOEL) as an MJO event transits phases 4 and 5. Since so few MJO events include a QBO phase pair change, QBO phase pair transitions over the MC are not analyzed further. Mean amplitudes of initially active MJO events are analyzed for each QBO phase pair primarily during their movement through RMM phases 4 and 5. Geographic regions neighboring the MC, the Indian Ocean (MJO phases 2 and 3) and the western Pacific Ocean (MJO phases 6 and 7), are included in this analysis to provide context to MJO event propagation 
across the MC. To reduce the effects of both the number of MJO days and the MJO propagation speed (e.g., Zhang and Zhang 2018), RMM amplitudes for each event are binned by and averaged for the entrance (when the MJO crosses from one phase to the next, e.g., the MJO exits phase 3 and enters phase 4) and midpoint (when the MJO is halfway through each phase) for each MJO phase, and those mean entrance and midpoint amplitudes are then averaged together for all MJO events in each QBO phase. This averaging removes the effects of individual MJO event propagation speed on the results. Statistical significance between QBOEM and QBOWM is tested at each phase's entrance and midpoint using a Welch's $t$ test (Son et al. 2017) to identify significant differences in MJO amplitude among these QBO phase pairs, where degrees of freedom are conservatively estimated as the lower number of MJO events between QBOEM and QBOWM at each point. All references to statistical significance are at the $95 \%$ confidence level. Mean MJO amplitude changes for events over the MC, averaged by QBO phase pair, are presented for the 42 boreal winter MJO events identified propagating as active through the MC with the RMM index. To confirm the validity of using the RMM index to characterize intraseasonal convection, Hovmöller diagrams of composite OLR anomalies with longitude for MJO events in each QBO phase pair are presented. These Hovmöller diagrams are created by calculating mean meridionally averaged OLR anomalies (from $15^{\circ} \mathrm{S}$ to $15^{\circ} \mathrm{N}$ ) for initially active boreal winter MJO events (from 10 days prior to 25 days after MJO entrance to RMM phase 4) during each QBO phase pair. The OLR data are freely available for download from the NOAA/ Earth System Research Laboratory (ESRL; https:// www.esrl.noaa.gov/psd/data/gridded/data.interp_OLR. $\mathrm{html}$ ). This entire analysis is repeated for the 35 boreal winter $\mathrm{MJO}$ events identified propagating as active through the MC with the OMI. Finally, mean MJO amplitude change over the MC by QBO phase pair is presented by seasonal subsets (DJF, MAM, JJA, and SON). During boreal summer (June-August), amplitude changes for the RMM, OMI, and BSISO indices are all presented.

\section{d. Considering the effect of ENSO}

Since the phase of QBO has been linked to the phase of ENSO (Gray et al. 1992; Taguchi 2010), and since MJO propagation seems to be most favored during the La Niña phase of ENSO (Kerns and Chen 2016), the analysis described in section $2 \mathrm{c}$ is repeated for neutral ENSO years. This removes potential influences of ENSO on observed MJO-QBO relationships. ENSO neutral was defined using the oceanic Niño index (ONI;
Kousky and Higgins, 2007). In the ONI, sea surface temperature (SST) anomalies from the Niño-3.4 region $\left(5^{\circ} \mathrm{S}-5^{\circ} \mathrm{N}, 120^{\circ}-170^{\circ} \mathrm{W}\right)$ of greater than $0.5^{\circ} \mathrm{C}$ or less than $-0.5^{\circ} \mathrm{C}$ for a period of 5 or more continuous months are identified as El Niño and La Niña, respectively. Neutral ENSO conditions occur in the absence of El Niño or La Niña conditions. The ONI SST data were obtained from the NOAA/Climate Prediction Center (CPC; http://origin.cpc.ncep.noaa.gov/products/ analysis_monitoring/ensostuff/ONI_v5.php).

\section{Results}

There are three primary components of this study. First, associations between QBO phase pair and atmospheric conditions such as zonal wind, vertical wind shear, and static stability are presented. Second, relationships between QBO phase pair and MJO are evaluated over the MC during boreal winter. These boreal winter relationships are then constrained for active MJO events and by neutral ENSO conditions. Finally, seasonality of the QBO-MJO association is considered as the relationship between QBO and MJO amplitude change is contrasted by season. Results are presented first for the RMM index, and then compared with results based on the OMI and BSISO indices.

\section{a. QBO phase-space analysis}

Downward propagation of the mean zonal wind through the stratosphere is apparent in vertical profiles for each of the eight QBO phases (Fig. 4). For example, during QBO phase A (Fig. 4a), there is an easterly wind maximum at $20 \mathrm{hPa}$. From QBO phases B-D (Figs. 4a,b), this easterly wind maximum propagates downward and dissipates near $100 \mathrm{hPa}$ as an upper-stratospheric westerly wind maximum develops (centered between 20 and $30 \mathrm{hPa}$ during QBO phase D; Fig. 4b). From QBO phases E-H (Figs. 4c,d), this westerly wind maximum propagates downward through the stratosphere and dissipates near $100 \mathrm{hPa}$, as a new easterly wind maximum develops at $10 \mathrm{hPa}$ and begins to propagate downward, returning to QBO phase A conditions. This downward momentum propagation is captured as counterclockwise movement through the QBO phase space (Fig. 3a). While mean zonal wind speeds vary by up to $15 \mathrm{~m} \mathrm{~s}^{-1}$ at $70 \mathrm{hPa}$ across the $8 \mathrm{QBO}$ phases (Fig. 4), all 8 QBO phases have similar mean zonal wind speeds at and below $100 \mathrm{hPa}$ (near the tropopause and in the troposphere).

The stratospheric zonal wind speeds vary when QBO phases are grouped into pairs (Fig. 5a), yielding vertical shear of the zonal winds that varies by QBO phase pair. Because the QBO is cyclical, these changes in zonal 

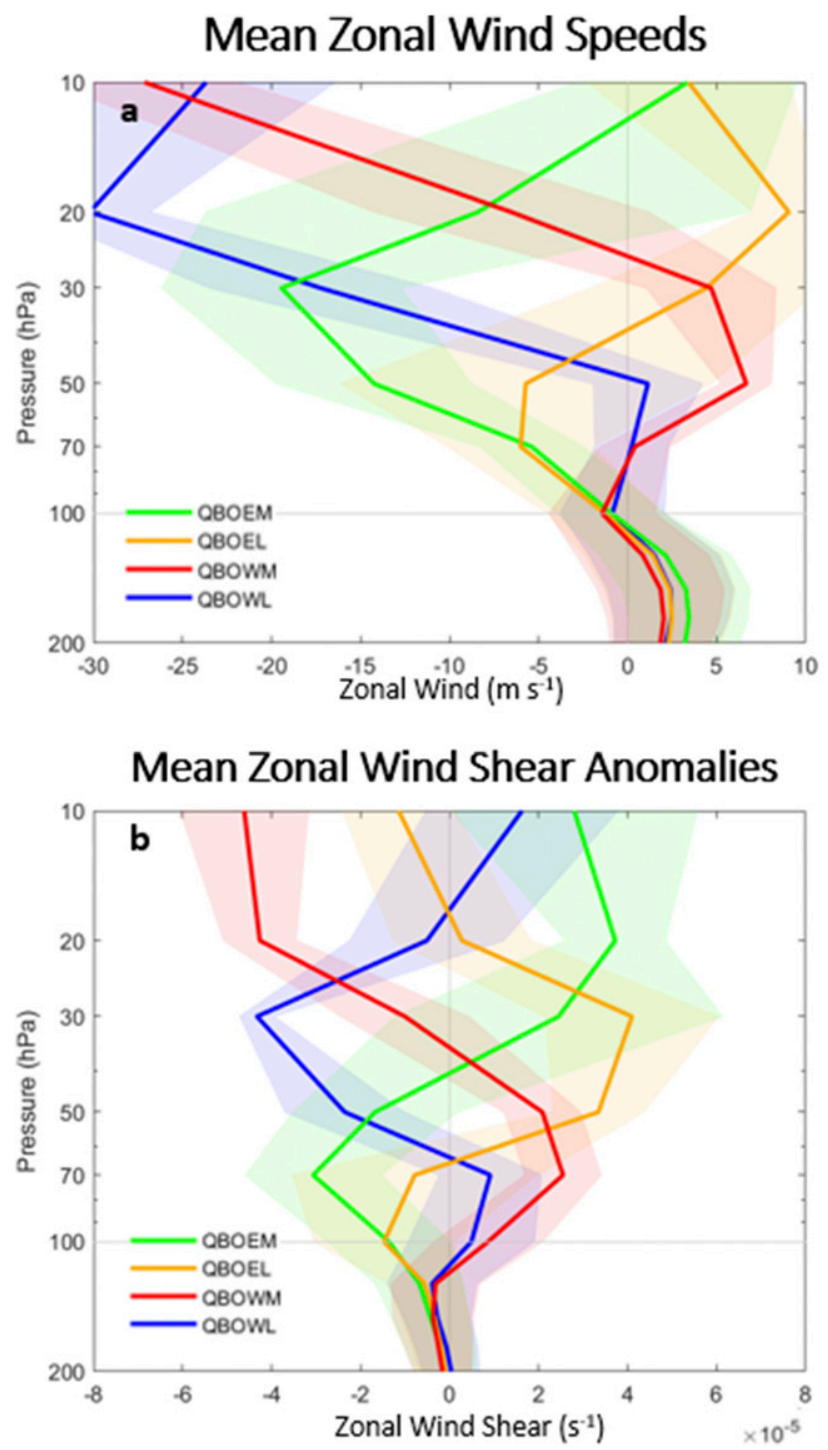
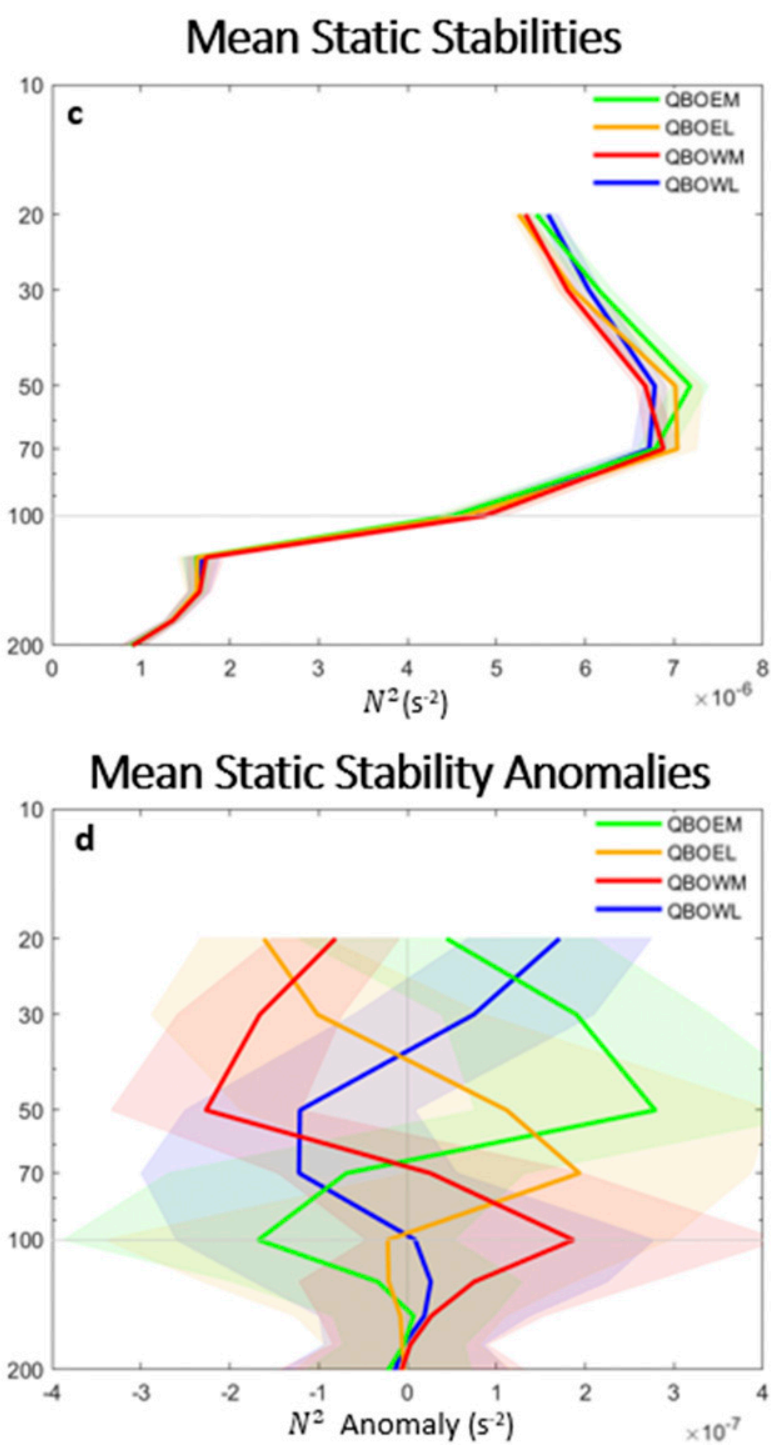

FIG. 5. (a) Mean zonal wind speeds, (b) mean zonal wind shear anomalies, (c) mean static stabilities $N^{2}$, and (d) static stability anomalies from 200 to $10 \mathrm{hPa}$ for each of the 4 QBO phase pairs for all days, 1980-2017. Shading indicates variability of one standard deviation. Static stability is not presented above $20 \mathrm{hPa}$ because of dataset limitations.

winds and the corresponding vertical wind shears over time result in vertical wind shear anomalies associated with each QBO phase pair (Fig. 5b). Specifically, zonal winds become more negative with height (shear anomalies are negative) from below the tropopause to the mid- and lower stratosphere during QBOEM and QBOEL, respectively, but become more positive with height (shear anomalies are positive) from below the tropopause to the mid- and lower stratosphere during QBOWM and QBOWL, respectively (Figs. 5a,b). These differences in QBO phase characteristics also extend to atmospheric static stability ( $N^{2}$; Fig. 5c) and to static stability anomalies (Fig. 5d). Although stratospheric static stability is positive (the atmosphere is stable) for all phase pairs (Fig. 5c), static stability anomalies vary significantly among phase pairs (Fig. 5d). For example, at $100 \mathrm{hPa}$, static stability anomalies are negative [indicating a less stable upper troposphere and lower stratosphere (UTLS)] during QBOEM and positive (indicating a more stable UTLS) during QBOWM (Fig. 5d). During QBOEL and QBOWL, 100-hPa stability anomalies are close to zero (indicating little difference from climatological UTLS stability).

These UTLS stability changes with QBO-driven vertical wind shear result from QBO modulation of lower-stratospheric temperatures. Stratospheric and 

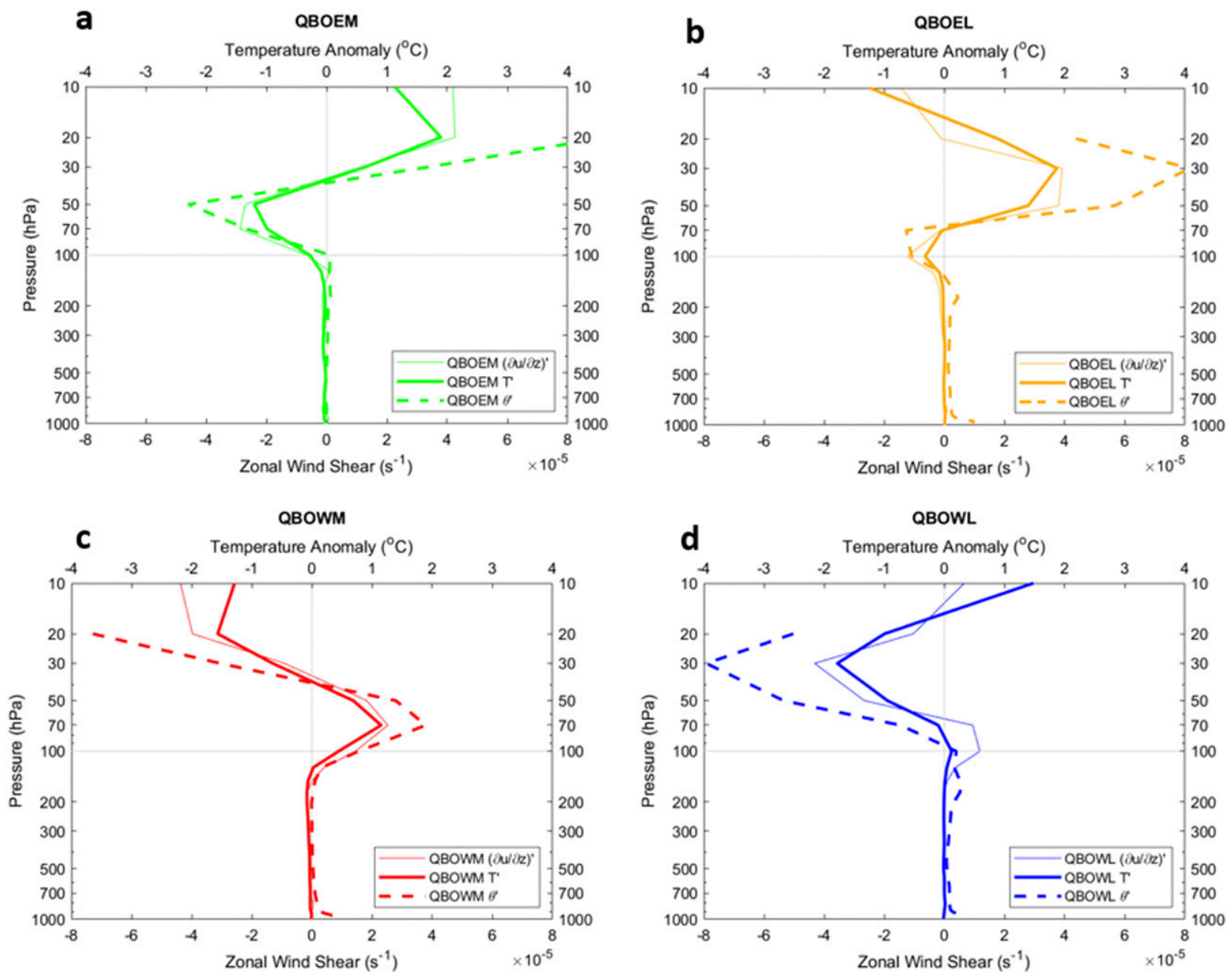

FIG. 6. Mean $\left(10^{\circ} \mathrm{S}-10^{\circ} \mathrm{N}, 0^{\circ}-360^{\circ}\right)$ zonal wind shear $\left(\mathrm{s}^{-1}\right.$; thin lines), temperature $\left({ }^{\circ} \mathrm{C}\right.$; thick lines), and potential temperature $(\mathrm{K}$; thick dashed lines) anomalies by QBO phase pair (QBOEM, QBOEL, QBOWM, and QBOWL), for all days, 1980-2017.

upper-tropospheric (above $200 \mathrm{hPa}$ ) temperature anomalies, potential temperature anomalies, and shear anomalies are proportional to one another (Fig. 6) [Eq. (A1) in the appendix]. Changes in vertical shear with height correspond to changes in temperature (and therefore stability) with height, and as a result, vertical shear of the stratospheric zonal winds and stratospheric stabilities are related as follows:

$$
\frac{\partial^{2} u}{\partial z^{2}}=-\frac{1}{\beta} \frac{\partial^{2} N^{2}}{\partial y^{2}}
$$

where $\partial^{2} u / \partial z^{2}$ is the change in shear of the stratospheric zonal winds with height $\left(\mathrm{s}^{-1} \mathrm{~m}^{-1}\right), \beta$ is the change in Coriolis with latitude $\left(\mathrm{s}^{-1} \mathrm{~m}^{-1}\right)$, and $\partial^{2} N^{2} / \partial y^{2}$ is the meridional curvature of the static stability $\left(\mathrm{s}^{-2} \mathrm{~m}^{-2}\right.$; see the appendix). This relationship can be extended to a proportionality of shear and stability anomalies, such that

$$
N^{2^{\prime}} \propto \frac{\partial}{\partial z}\left(\frac{\partial u}{\partial z}\right)^{\prime}
$$

where $N^{2^{\prime}}$ is the static stability anomaly $\left(\mathrm{s}^{-2}\right)$, and $\partial / \partial z(\partial u / \partial z)^{\prime}$ is the change of anomalous shear with height $\left(\mathrm{s}^{-2}\right)$. For example, during QBOEM, shear anomalies are easterly in the lower stratosphere and become more easterly with height $\left[\partial / \partial z(\partial u / \partial z)^{\prime}<0\right]$ from 125 to $70 \mathrm{hPa}$ (green line, Fig. 5b). Conversely, during QBOWM, shear anomalies are westerly in the UTLS and become more westerly with height $\left[\partial / \partial z(\partial u / \partial z)^{\prime}>0\right]$ from 125 to $70 \mathrm{hPa}$ (red line, Fig. 5b). Therefore, the zonal wind regimes associated with QBOEM and QBOWM drive negative and positive static stability anomalies, respectively, in the UTLS, in agreement with Hendon and Abhik (2018) who connected cold temperature anomalies found at $100 \mathrm{hPa}$ during the easterly phase of the QBO to MJO eastward 

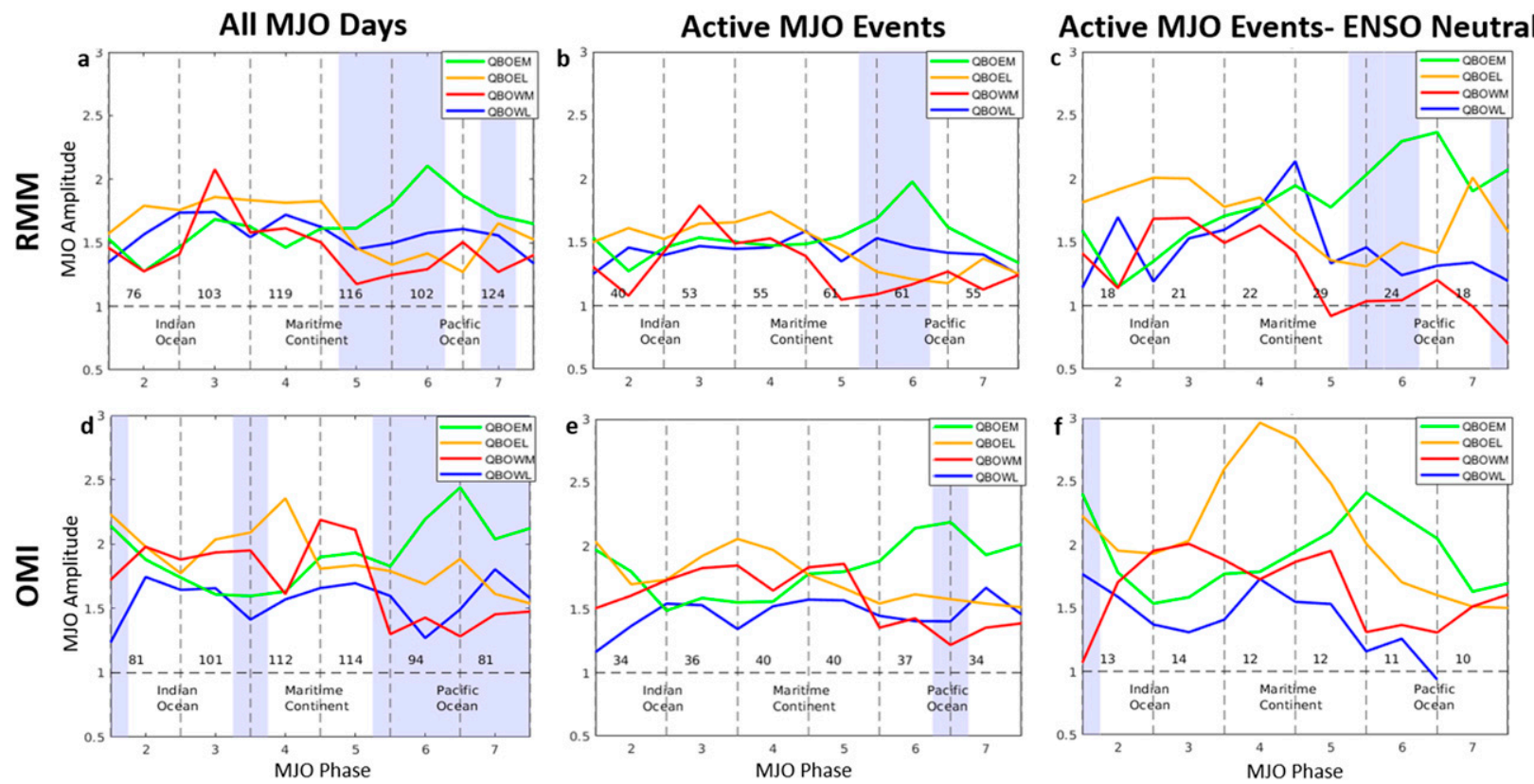

FIG. 7. Mean MJO amplitudes of each QBO phase pair from MJO phases 2-7 for (a),(d) all MJO days; (b),(e) all initially active MJO events; and (c),(f) all initially active MJO events during neutral ENSO conditions that entered MJO phase 4 active during boreal winter (DJF) from 1980 to 2017. MJO activity was identified using the (a)-(c) RMM and (d)-(f) OMI indices. The horizontal dashed line in each panel denotes the threshold for MJO activity, and numbers above that dashed line represent the sample size of MJO events in each MJO phase. Gray shading denotes MJO phases where MJO amplitudes for QBOEM and QBOWM are statistically significantly different from one another at the $95 \%$ confidence level.

propagation. This relationship does not extend to the mid- to lower troposphere below $200 \mathrm{hPa}$, where winds are increasingly westerly between 600 and $200 \mathrm{hPa}$ (Fig. 4) and wind shear anomalies (Fig. 6) are nearly zero during all QBO phase pairs. Therefore, mechanisms by which QBO-driven stability changes may affect MJO amplitude are concentrated in the stratosphere and upper troposphere and will be examined at $100 \mathrm{hPa}$ in forthcoming sections.

\section{b. QBO-MJO amplitude relationships during boreal winter}

During boreal winter, the mean MJO RMM amplitude (mean of all MJO days of each of the 42 events) at the exit of MJO phase 5 is higher than the mean RMM amplitude at the start of phase 4 during QBOEM (when midstratospheric winds are easterly; green line, Fig. 7a). Conversely, the mean RMM amplitude is lower at the exit of phase 5 than the start of phase 4 during QBOWM (when midstratospheric winds are westerly; red line, Fig. 7a). The RMM amplitude at the entrance to phase 4 is statistically similar for both QBOEM and QBOWM; however, QBOEM RMM amplitudes exceed QBOWM RMM amplitudes throughout most of phases 4, 5, and 6 (Fig. 7a), including a difference of nearly +0.5 at the exit of phase 5 , which is statistically significantly different at the $95 \%$ confidence level. This indicates two relationships between the QBO and RMM MJO during boreal winter: first, the MJO is stronger during QBOEM than QBOWM (higher and lower RMM amplitudes, respectively) over most of the MC and western Pacific Ocean (WP); second, the MJO strengthens during QBOEM and weakens during QBOWM (increasing and decreasing RMM amplitudes, respectively) while crossing the MC. In contrast, MJO events during QBOEL and QBOWL do not develop significant RMM amplitude differences while moving over the MC (Fig. 7a).

Because the MJO is both more active and slower moving during QBOEM than QBOWM (RMM amplitude greater than 1.0 on $75 \%$ of QBOEM days vs on $59 \%$ of QBOWM days; see also Zhang and Zhang 2018), the above analysis was repeated for only MJO events that entered RMM phase 4 as active (amplitude greater than or equal to 1). Additionally, RMM amplitudes for each of these active MJO events were first binned and averaged by MJO phase before being averaged for all events in the same QBO phase pair, which served to reduce effects of propagation speed. The relationships between QBOEM and QBOWM for these MJO events (Fig. 7b) are consistent with those illustrated above for MJO days (i.e., RMM MJO amplitudes are significantly higher over the 
eastern MC and WP during QBOEM than QBOWM, and the MJO generally strengthens during QBOEM and weakens during QBOWM while crossing the MC). Both relationships continue to hold when considering only the 18 active RMM MJO events that occurred during neutral-only ENSO conditions (Fig. 7c) (i.e., RMM MJO amplitudes are higher during QBOEM than QBOWM throughout most of the $\mathrm{MC}$ and $\mathrm{WP}$, and the $\mathrm{MJO}$ again generally strengthens during QBOEM and weakens during QBOWM while crossing the MC). However, as discussed in Lee and Klingaman (2018), the QBO may be influenced by strong El Niño events up to 2-4 years after an El Niño event decays (Christiansen et al. 2016); those time lags were not considered in this study.

One previously discussed weakness of the RMM index is its bias toward circulation anomalies (Straub 2013), meaning that it is possible for RMM amplitude to change without corresponding material changes in the convection. To examine the evolution of deep convection while RMM-identified MJO events move across the MC, Hovmöller diagrams of OLR during QBOEM and QBOWM are presented (Fig. 8). OLR anomalies are more negative (indicating stronger convection) upon MJO phase 4 entrance in QBOEM than QBOWM, and this difference in mean convection increases as the $\mathrm{MJO}$ active envelope propagates eastward over the MC and WP. This difference in OLR confirms that differences in RMM amplitude between QBOEM and QBOWM are connected to differences in convection.

Physical mechanisms behind the zonal differences in RMM MJO magnitude and enhanced MJO convection during boreal winter within each QBO phase pair (Figs. 7 and 8 ) can be understood by examining 100-hPa static stability anomalies across the $\mathrm{MC}$ and WP (Figs. 9a,b). During QBOEM, when RMM amplitudes increase across the eastern MC and WP (Figs. 7a-c), the 100-hPa static stability anomalies are found to decrease with eastward extent along the equator (Fig. 9a). Conversely, during QBOWM, when RMM amplitudes decrease across the eastern MC and WP, the 100-hPa static stability anomalies are found to increase with eastward extent along the equator (Fig. 9b). These static stability anomalies, which are related to the QBO through change of wind shear anomalies with height [Eq. (4)], correspond to enhanced vertical motion during QBOEM and suppressed vertical motion during QBOWM associated with the propagation of the active envelope across the eastern MC and WP. This is in agreement with Hendon and Abhik (2018), who found enhanced upward vertical motion over those areas during easterly QBO. The spatial structure in $100-\mathrm{hPa}$ stability anomalies remains similar when considering only ENSO-neutral conditions (not shown).
As in the RMM index, initially active MJO amplitudes in the OMI develop significant differences depending on QBO phase (Figs. 7d,e). However, in the OMI, differences in QBOEM and QBOWM MJO amplitudes develop later (farther east) than in the RMM index, beginning when the MJO reaches the middle of OMI phase 5 and continuing through phases 6 and 7 (corresponding to MJO active envelope passage over the eastern MC and WP) (Figs. 7d,e). This relationship remains consistent when considering only the 14 active OMI MJO events that occurred during the neutral phase of ENSO (Fig. 7f). One reason for this eastward displacement may reside in differences between the indices: both zonal winds and OLR are included in the RMM index, while only OLR is considered in the OMI. The stability changes near $100 \mathrm{hPa}$ associated with the QBO likely precondition the UTLS for reduced stability during QBOEM and enhanced stability during QBOWM. That preconditioning thereby facilitates stronger upward vertical motion during QBOEM and weaker upward vertical motion during QBOWM (and correspondingly stronger zonal MJO circulation during QBOEM and weaker MJO circulation during QBOWM), which is projected onto the RMM index but may not yet be apparent in the OLR-based OMI. Mean OLR anomalies for OMI-identified events were also analyzed (not shown), yielding OLR differences among QBO phases similar to the differences in OMI amplitudes presented in Figs. 7d-f. Because moisture availability over the western Pacific Ocean affects longitudinal variability of MJO convective activity, additional analysis of MJO amplitude during El Niño and La Niña ENSO phases is suggested for future work.

\section{c. QBO-MJO amplitude relationship seasonality}

The QBO-MJO relationships established for boreal winter change during boreal spring and summer. During boreal winter, RMM MJO events that enter phase 4 during QBOEM strengthen over the MC on average by an amplitude change [Eq. (1)] of +0.14 , and events that enter phase 4 during QBOWM weaken over the $\mathrm{MC}$ on average by -0.49 (Fig. 10a). The trend in RMM MJO amplitude changes during QBOEM reverses during boreal spring, when active MJO events weaken on average by -0.78 (Fig. 10a). Additionally, boreal spring MJO events that enter phase 4 during QBOWM weaken on average by only -0.36 (Fig. 10a; note that the QBOWM mean amplitude change is not statistically significantly different from climatology). During boreal summer, neither QBOEM nor QBOWM strengthens or weakens significantly compared to RMM climatological amplitude changes. This lack of a statistically significant relationship may be due to the cross-equatorial 

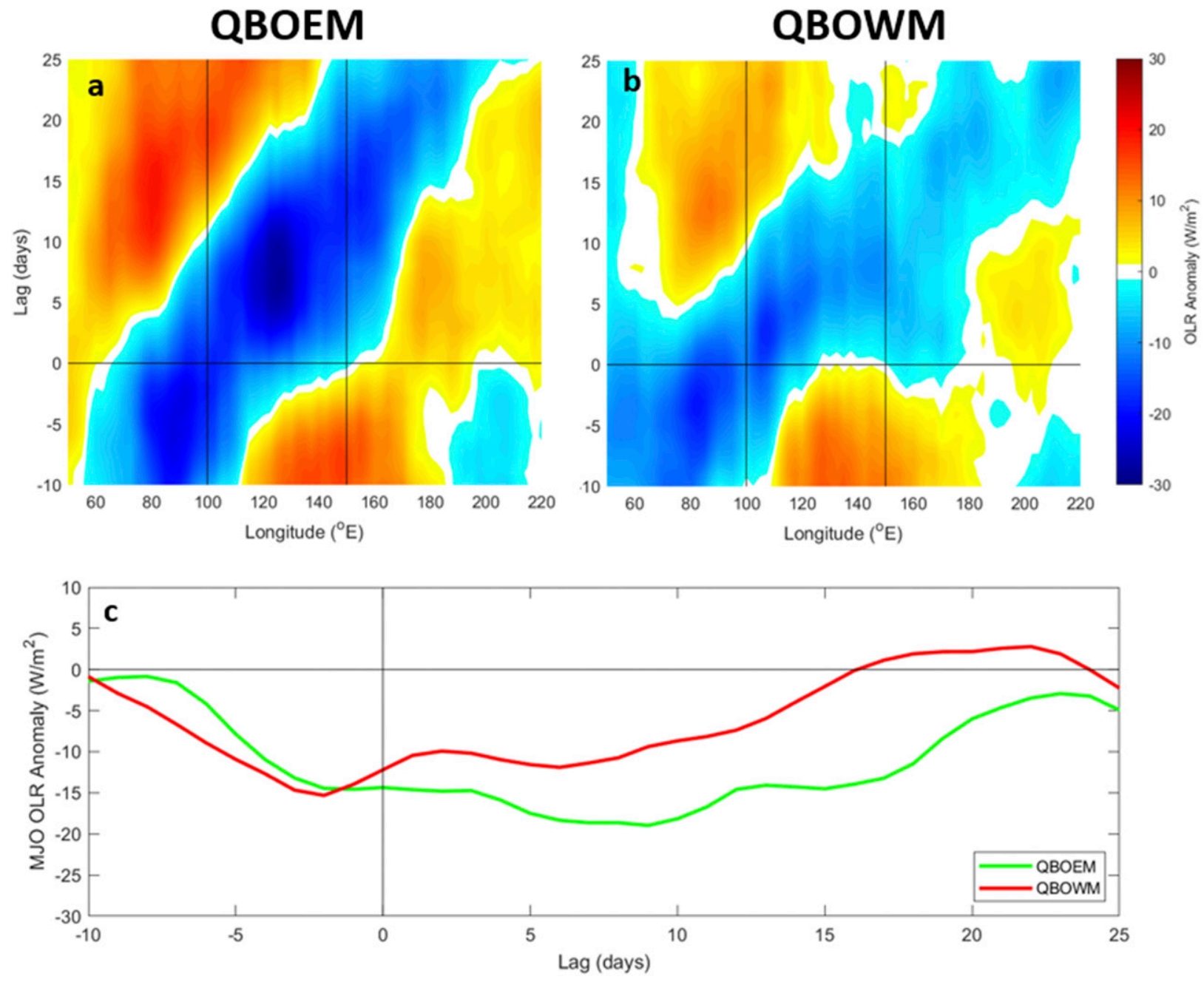

FIG. 8. Hovmöller diagrams of OLR averaged meridionally from $15^{\circ} \mathrm{S}$ to $15^{\circ} \mathrm{N}$ for initially active MJO events from 1980 to 2017 identified with the RMM index during (a) QBOEM and (b) QBOWM. (c) Time series of mean OLR within the MJO active envelope for the same MJO events for QBOEM and QBOWM. Lag represents days relative to entrance to MJO phase 4.

procession of the BSISO, which complicates the MJO signal and renders both the RMM and OMI indices less capable of tracking this BSISO-mode convection across the MC. Active BSISO events, however, display the opposite characteristics during boreal summer than are found in active RMM MJO events during boreal winter (Fig. 10a). Specifically, amplitudes weaken during QBOEM (by -0.18) and strengthen during QBOWM (by +0.05 , although as with boreal spring RMM MJO events, the QBOWM relationship is not statistically significant). Finally, RMM MJO events during boreal autumn do not exhibit a significant relationship between MJO amplitude changes over the MC and QBO phase pair. For MJO events identified using the OMI (Fig. 10b), seasonality of the QBO-MJO relationship between December and August is similar to that which is observed in the RMM index, except for boreal summer, during which OMI MJO event amplitude changes mirror those for BSISO events. In boreal autumn, OMI amplitudes significantly weaken during QBOEM and strengthen during QBOWM over the MC, which is the opposite of what is suggested in the RMM index for the same period (Fig. 10b).

Seasonal variations in QBO-driven UTLS static stability anomalies are consistent with the seasonal variations in MJO amplitude across the MC and WP. Specifically, zonal differences in static stability anomalies are consistent with MJO amplitude changes across the eastern MC and WP during boreal winter, and meridional differences in static stability anomalies are consistent with MJO and BSISO amplitude changes across the same region during boreal summer. MJO events transit eastward along the equator and are evaluated between $15^{\circ} \mathrm{S}$ and $15^{\circ} \mathrm{N}$ in the RMM index. 

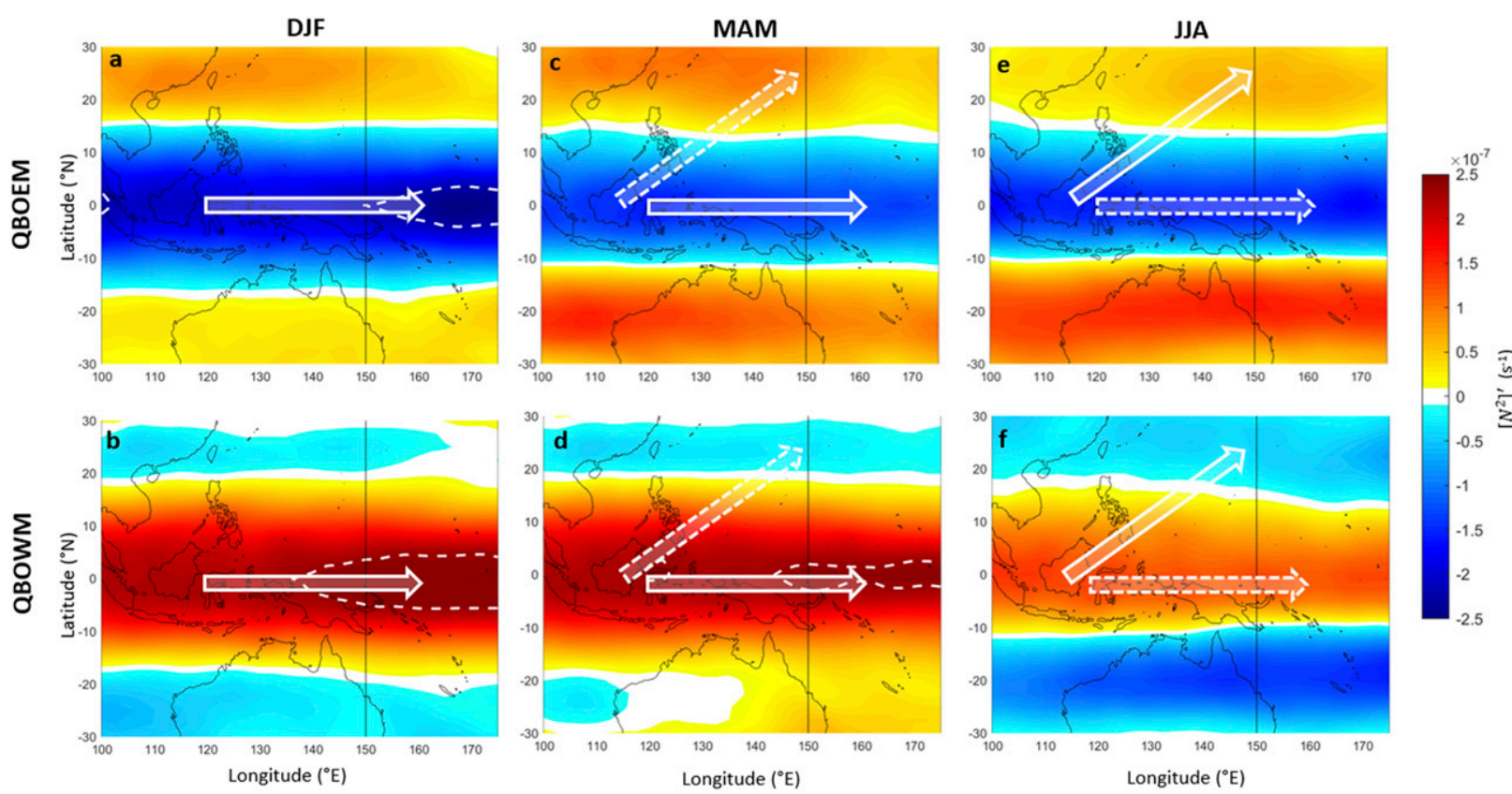

FIG. 9. Mean (a),(b) boreal winter; (c),(d) boreal spring; and (e),(f) boreal summer 100-hPa static stability ( $\left.N^{2}\right)$ anomalies for (a),(c),(e) QBOEM and (b),(d),(f) QBOWM from 1980 to 2017, bounded meridionally by $30^{\circ} \mathrm{S}$ and $30^{\circ} \mathrm{N}$ and zonally by $100^{\circ}$ and $200^{\circ} \mathrm{E}$. Dashed white contours at $-2.2 \times 10^{-7}$ and $2.4 \times 10^{-7}$ highlight the largest stability anomaly magnitudes, black vertical lines denote the approximate eastern boundary of the Maritime Continent $\left(150^{\circ} \mathrm{E}\right)$, and white arrows denote typical MJO and/or BSISO propagation during each season (solid and dashed arrows represent primary and secondary propagation modes for each season, respectively).

During boreal summer, however, the dominant mode of intraseasonal convection becomes the BSISO (Lee et al. 2013), and instead of moving eastward along the equator, this feature propagates northeastward through the BSISO index domain, which extends farther northward and spans greater latitudinal extent $\left(10^{\circ} \mathrm{S}-40^{\circ} \mathrm{N}\right)$. As $\mathrm{MJO}$ events move eastward along the equator in boreal winter, they enter regions of lower UTLS static stability during QBOEM and higher UTLS static stability during QBOWM (Figs. 9a,b). As BSISO events move northeastward during boreal summer, however, they enter regions where the UTLS static stability signs reverse, and anomalies are higher during QBOEM and lower during QBOWM (Figs. 9e,f). In doing so, many of these BSISO events exit the northern boundary $\left(15^{\circ} \mathrm{N}\right)$ of the RMM index, resulting in decreases in RMM amplitudes not because the convection feature itself has dissipated, but rather because the convection and associated circulation have largely exited the RMM domain. This feature-tracking aspect of BSISO indices is one reason they have become a preferred method to characterize intraseasonal oscillations over the $\mathrm{MC}$ in boreal summer (Kikuchi et al. 2012).

Boreal spring marks a transition period as the eastward propagation of $\mathrm{MJO}$ events prevalent during boreal winter becomes less dominant compared to the northeastward propagation of BSISO events prevalent during boreal summer. Since static stability anomaly magnitudes decay away from the equator (Figs. 9c,d), any northward motion of these events would result in either increased stabilities and corresponding decreases in RMM amplitudes during QBOEM or decreased stabilities and corresponding increases in RMM amplitudes during QBOWM. However, the mix of eastward- and northeastward-propagating intraseasonal convective events during boreal spring (Kikuchi et al. 2012) makes RMM amplitude changes across the MC difficult to interpret relying solely on static stability anomalies.

Additionally, one characteristic that is not explained through these seasonal shifts in $100-\mathrm{hPa}$ static stability anomalies is the reversal in relative RMM amplitudes between QBOEM and QBOWM after boreal winter. During boreal winter, mean QBOEM RMM amplitudes are higher than mean QBOWM RMM amplitudes over phases 4 and 5 by +0.23 , and during boreal spring and summer, mean QBOEM RMM amplitudes are lower than mean QBOWM RMM amplitudes over the same region by -0.31 and -0.09 , respectively (not shown). The boreal winter relationship is consistent with the $100-\mathrm{hPa}$ static stability anomalies, which are proportional to vertical changes in QBO-driven wind shear 

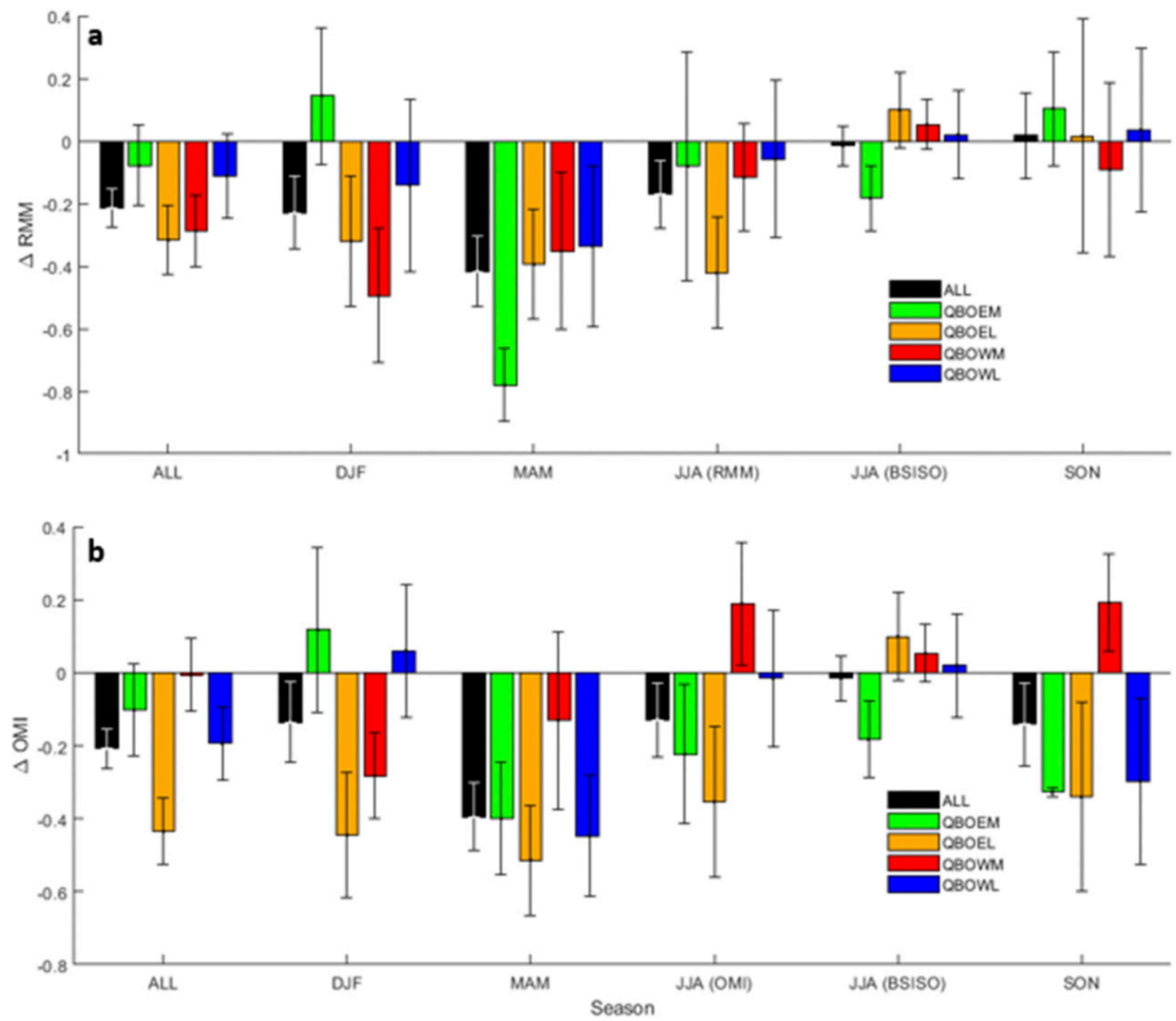

FIG. 10. Mean (a) RMM and (b) OMI MJO amplitude change [Eq. (1)] for initially active MJO events from 1980 to 2017, binned by QBO phase pair and season. Mean BSISO amplitude change is presented in both panels for boreal summer only. Error bars represent the standard error of MJO amplitudes for each QBO phase-season combination.

for all seasons, but the boreal spring and summer relationships are not consistent. Consequently, there are likely other seasonally dependent mechanisms that influence RMM amplitudes, other than UTLS static stability (including moisture availability and lower- and midtropospheric stability). Finally, seasonal variations in MJO amplitude changes over the MC and UTLS stability anomalies among QBO phases hold when constrained to consider only neutral ENSO conditions (not shown).

\section{Conclusions and discussion}

QBO influences on the MJO were evaluated over the Maritime Continent between 1980 and 2017, first for boreal winter, and then extended to all seasons. Potential relationships between the vertical structure of QBOdriven zonal winds and MJO and BSISO amplitudes were explored by categorizing QBO activity with an EOF-derived phase space of stratospheric zonal winds and MJO activity with the RMM, OMI, and BSISO indices.

The strongest relationships between the QBO and $\mathrm{MJO}$ are found when midstratospheric winds are easterly (QBOEM) and westerly (QBOWM), conditions that were present $46 \%$ of the time between 1980 and 2017. Increased RMM amplitudes during QBOEM correspond to larger negative OLR anomalies, indicating stronger convection associated with the MJO 
active envelope. Conversely, decreased RMM amplitudes during QBOWM correspond to smaller negative OLR anomalies, indicating weaker convection associated with the MJO active envelope. Changes in zonal wind shear with height are greatest over the UTLS (between 125 and $70 \mathrm{hPa}$ ) in these two phases, which decreased $100-\mathrm{hPa}$ static stability anomalies, enhanced upward vertical motion, and increased RMM amplitudes during QBOEM, but increased 100-hPa stability anomalies, suppressed upward vertical motion, and decreased RMM amplitudes during QBOWM. These stability anomalies vary both spatially and temporally. Relative minima in static stability are consistently present in zonal bands along the equator during QBOEM, and maxima in static stability are consistently present during QBOWM (as also found in Yoo and Son 2016; Son et al. 2017; Hendon and Abhik 2018), and the static stability anomalies reverse in sign poleward of about $15^{\circ}$ latitude. Zonal gradients in static stability are also present but are small compared to meridional gradients, particularly near the reversals in sign beyond each equatorial band. Consequently, active MJO events, which track eastward along the equator, experience changes in RMM amplitude corresponding to zonal changes in $100-\mathrm{hPa}$ static stability. As MJO events propagate eastward over the MC during boreal winter, static stability anomalies increase in magnitude over the eastern MC and WP. That is, static stability anomalies decrease during QBOEM and increase during QBOWM, corresponding to a less stable atmosphere and increased RMM amplitudes over the eastern MC and WP (RMM phases 5 and 6) during QBOEM, and a more stable atmosphere and decreased RMM amplitudes over the same region during QBOWM. These differences in 100-hPa static stability anomalies are consistent with regional tendencies of the boreal winter QBO-MJO relationship identified in this study, and are also in agreement with Zhang and Zhang (2018). This zonal heterogeneity of QBO-driven UTLS stability supports the notion of QBO-driven stability changes modulating the QBO-MJO relationship.

Differences between these results and those of previous studies [e.g., a zonally homogenous QBO-MJO relationship; Yoo and Son (2016); and no significant differences in MJO amplitude with QBO conditions when only considering active MJO events; Zhang and Zhang (2018)] may stem from the QBO EOF analysis used in this study. There are differences between the stratospheric zonal wind regimes (and consequently, MJO conditions) in the EOF analysis of this study and the 50-hPa $u$ index of other MJO-QBO studies. Categorizing QBO-driven stratospheric zonal winds in the context of both zonal wind direction and height more precisely constrains the QBO-MJO relationship by stratospheric zonal wind structure (and therefore UTLS stability), revealing significant relationships that may not be apparent when QBO conditions are more broadly binned.

Seasonal differences in QBO-MJO relationships are most noticeable between boreal winter and summer, as the intraseasonal convective events shift from primarily eastward moving (as in the MJO during boreal winter) to primarily northeastward moving (as in the BSISO during boreal summer). This seasonal shift results in the circulation and convection anomalies passing through different spatial gradients in static stability. As these events propagate poleward of $15^{\circ} \mathrm{N}$ during boreal summer, they exit the domain of the RMM and OMI indices, resulting in EOF projections that may not fully capture the circulation or convection. As the boreal summer events propagate poleward into regions of opposite stability, their amplitudes (identified using the BSISO index) decrease during QBOEM in accordance with increased UTLS stability, and increase during QBOWM in accordance with decreased UTLS stability. This difference in propagation, combined with a reversal in anomalous meridional static stability gradients beyond about $15^{\circ}$, may explain the differences in amplitude changes observed among the RMM, OMI, and BSISO indices. Finally, both boreal spring and autumn are transition seasons (Kikuchi et al. 2012), when intraseasonal convection tracks can vary between eastward and northeastward, and therefore results were mixed during these seasons.

Repeating the analysis for MJO events identified with the OMI yielded QBO-MJO relationships that were similar to those identified in the RMM, with two key differences. First, during boreal winter, as the MJO transits eastward, peak MJO amplitude differences between QBOEM and QBOWM occur farther east in the OMI than in the RMM index. Second, during boreal summer, as the BSISO becomes more dominant and propagates northeastward, OMI MJO events strengthen significantly during QBOWM, similar to the relationships detected with the BSISO index, and unlike the weakening suggested by the RMM index during QBOWM. These zonal and meridional differences in the QBO-MJO relationship between the RMM and OMI indices may be due to inherent differences in how these indices quantify the MJO. Specifically, eastward propagation of MJO events across the MC through the RMM phase space occurs with an increase in the second principle component (RMM2), while the first principle component (RMM1) remains sufficiently positive to retain an amplitude of 1.0 or greater. Because zonal wind anomalies over the MC project strongly onto RMM2 (WH04), RMM amplitude changes over the $\mathrm{MC}$ in particular may reflect changes in zonal MJO 
circulation, rather than changes in MJO-associated convective activity. During boreal winter, increases in MJO upward vertical motion caused by QBO-driven instability during QBOEM and decreases in MJO upward vertical motion during QBOWM would affect zonal MJO circulation in a manner projected onto the RMM index [since changes in the vertical wind would be compensated for by changes in the horizontal (zonal) wind if mass is to be conserved]. During boreal summer, diminished zonal circulation (corresponding to an increased meridional circulation component caused by the northeastward propagation of the BSISO) may project onto the RMM as decreased amplitudes, regardless of actual increases or decreases in convection and circulation associated with the BSISO. The OMI is also more capable of tracking the northward progression of BSISO-mode convection because the EOF analysis is applied to two-dimensional OLR anomalies, rather than meridionally averaged OLR (Kiladis et al. 2014). Additionally, the domain of the OMI extends farther northward than the RMM index $\left(20^{\circ} \mathrm{N}\right.$ vs $\left.15^{\circ} \mathrm{N}\right)$ and would therefore capture more of the northeastwardpropagating BSISO-mode convection. Together, these differences in methodologies between the RMM and OMI indices may account for the differences observed in the QBO-MJO relationships.

Several aspects surrounding the differences in the QBO-MJO relationships detected in this and previous studies could be investigated further. For example, while results for both the RMM and OMI indices remain largely unchanged when considering only MJO events that occurred during neutral ENSO conditions for all seasons, additional work is required to identify possible effects arising from ENSO polarity (e.g., La Niña or El Niño). Additionally, the time lags between ENSO phases (Lee and Klingaman 2018) may also affect the QBOMJO relationship. Moreover, multiscale interactions with other modes of atmospheric and oceanic variability, such as the diurnal precipitation cycle and monsoonal cycles, were not considered here, and these may modulate the QBO-MJO relationship. Furthermore, the focus of this study was on connections between the QBO and the MJO active (enhanced) convective envelope, and relationships between the $\mathrm{QBO}$ and the MJO suppressed envelope could be considered. Finally, the geographic scope of this analysis could be expanded beyond the $\mathrm{MC}$ to better understand the seasonal variability in QBO impacts on the MJO worldwide.

Acknowledgments. The authors are grateful for the funding provided by the Office of Naval Research Propagation of Intra-Seasonal Tropical Oscillations (ONR PISTON) Award N0001416WX01752 and the USNA
Trident Scholar program. The authors also appreciate the helpful comments of the two external reviewers.

\section{APPENDIX}

\section{Relationship between Changes in Vertical Shear with Height and Horizontal Changes in Static Stability}

Deriving the relationship between changes in vertical shear of zonal winds and stability begins with the thermal wind equation for an equatorial beta-plane [Eq. (A1)], where $u$ is the zonal wind speed $\left(\mathrm{m} \mathrm{s}^{-1}\right), z$ is height, $R$ is the dry air gas constant $\left(287 \mathrm{~J} \mathrm{~kg}^{-1} \mathrm{~K}^{-1}\right), \beta$ is the change in Coriolis with latitude, $H$ is the atmospheric scale height $(\mathrm{m}), T$ is the temperature $(\mathrm{K})$, and $y$ is meridional position $(\mathrm{m})$. This equation has been used in numerous studies relating QBO-driven zonal wind and temperature variations (e.g., Baldwin et al. 2001):

$$
\frac{\partial u}{\partial \mathrm{z}}=\frac{-R}{\beta H} \frac{\partial^{2} T}{\partial y^{2}} .
$$

Taking the derivative of Eq. (A1) with respect to height $z$, expanding the partial derivatives with product and quotient rules, and consolidating the meridional curvature $\left(\partial^{2} / \partial y^{2}\right)$ terms restates the thermal wind balance as Eq. (A2):

$$
\frac{\partial^{2} u}{\partial z^{2}}=-\frac{1}{\beta} \frac{\partial^{2}}{\partial y^{2}}\left[\frac{R}{H}\left(\frac{\partial T}{\partial z}-\frac{T}{H} \frac{\partial H}{\partial z}\right)\right] .
$$

In Eq. (A2), $R / c_{p}$ (where $c_{p}$ is the specific heat capacity of dry air with respect to constant pressure, $\mathrm{J} \mathrm{kg}^{-1} \mathrm{~K}^{-1}$ ) can be substituted for $-\partial H / \partial z$ [Eq. (A8)] by first solving the scale height relationship [Eq. (A3)] for $z$ to yield Eq. (A4):

$$
\begin{aligned}
P & =P_{o} e^{-z / H} \\
(H) \ln \left(\frac{P}{P_{o}}\right) & =-z
\end{aligned}
$$

Expressing the hypsometric equation [Eq. (A5)] in terms of height $z$ at pressure $P$ by letting $z_{2}=z, z_{1}=0, P_{2}=P$, and $P_{1}=P_{o}$ yields Eq. (A6) as follows:

$$
\begin{array}{r}
z_{2}-z_{1}=\frac{R T}{g} \ln \left(\frac{P_{1}}{P_{2}}\right), \\
z=\frac{R T}{g} \ln \left(\frac{P_{o}}{P}\right) .
\end{array}
$$

Substituting Eq. (A6) into Eq. (A4), taking the derivative with respect to height $z$, and substituting the atmospheric lapse rate equation [Eq. (A7)] links the 
change in scale height $H$ with altitude $z$ to the quotient of the dry air gas constant $R$ and specific heat capacity at constant pressure $\left[c_{p} ;\right.$ Eq. (A8)]:

$$
\begin{aligned}
\frac{g}{c_{p}} & =-\frac{\partial T}{\partial z}, \\
\frac{\partial H}{\partial z} & =\frac{-R}{c_{p}} .
\end{aligned}
$$

Substituting Eq. (A8) into Eq. (A2) restates the thermal wind balance as in Eq. (A9):

$$
\frac{\partial^{2} u}{\partial z^{2}}=-\frac{1}{\beta} \frac{\partial^{2}}{\partial y^{2}}\left[\frac{R}{H}\left(\frac{\partial T}{\partial z}+\frac{R T}{c_{p} H}\right)\right] .
$$

Finally, substituting the static stability equation [Eq. (A10)] into Eq. (A9) links change in zonal wind shear with height to the meridional curvature of atmospheric stability at the same height [Eq. (A11), which is Eq. (3) in the main body of this paper]:

$$
\begin{aligned}
N^{2} & \equiv \frac{R}{H}\left(\frac{\partial T}{\partial z}+\frac{R T}{c_{p} H}\right), \\
\frac{\partial^{2} u}{\partial \mathrm{z}^{2}} & =-\frac{1}{\beta} \frac{\partial^{2} N^{2}}{\partial y^{2}} .
\end{aligned}
$$

\section{REFERENCES}

Baldwin, M. P., and Coauthors, 2001: The quasi-biennial oscillation. Rev. Geophys., 39, 179-229, https://doi.org/10.1029/ 1999RG000073.

Christiansen, B., S. Yang, and M. S. Madsen, 2016: Do strong warm ENSO events control the phase of the stratospheric QBO? Geophys. Res. Lett., 43, 10 489-10 495, https://doi.org/ 10.1002/2016GL070751.

Collimore, C. C., D. W. Martin, M. H. Hitchman, A. Huesmann, and D. E. Waliser, 2003: On the relationship between the QBO and tropical deep convection. J. Climate, 16, 2552-2568, https://doi. org/10.1175/1520-0442(2003)016<2552:OTRBTQ>2.0.CO;2.

Dee, D. P., and Coauthors, 2011: The ERA-Interim reanalysis: Configuration and performance of the data assimilation system. Quart. J. Roy. Meteor. Soc., 137, 553-597, https://doi.org/ 10.1002/qj.828.

DeMott, C. A., B. O. Wolding, E. D. Maloney, and D. A. Randall, 2018: Atmospheric mechanisms for MJO decay over the Maritime Continent. J. Geophys. Res. Atmos., 123, 5188-5204, https://doi.org/10.1029/2017JD026979.

Feng, J., T. Li, and W. Zhu, 2015: Propagating and nonpropagating $\mathrm{MJO}$ events over Maritime Continent. J. Climate, 28, 8430-8449, https://doi.org/10.1175/JCLI-D-150085.1.

Fraedrich, K., S. Pawson, and R. Wang, 1993: An EOF analysis of the vertical-time delay structure of the quasi-biennial oscillation. J. Atmos. Sci., 50, 3357-3365, https://doi.org/10.1175/ 1520-0469(1993)050<3357:AEAOTV>2.0.CO;2.
Gray, W. M., J. D. Sheaffer, and J. A. Knaff, 1992: Influence of the stratospheric QBO on ENSO variability. J. Meteor. Soc. Japan, 70, 975-995, https://doi.org/10.2151/jmsj1965.70.5_975.

Gushchina, D., and B. Dewitte, 2012: Intraseasonal tropical atmospheric variability associated with the two flavors of El Niño. Mon. Wea. Rev., 140, 3669-3681, https://doi.org/ 10.1175/MWR-D-11-00267.1.

Hagos, S. M., C. Zhang, Z. Feng, C. D. Burleyson, C. D. Mott, B. Kerns, J. J. Benedict, and M. N. Martini, 2016: The impact of the diurnal cycle on the propagation of Madden-Julian Oscillation convection across the Maritime Continent. J. Adv. Model. Earth Syst., 8, 1552-1564, https://doi.org/10.1002/ 2016MS000725.

Hendon, H. H., and S. Abhik, 2018: Differences in vertical structure of the Madden-Julian oscillation associated with the quasi-biennial oscillation. Geophys. Res. Lett., 45, 4419-4428, https://doi.org/10.1029/2018GL077207.

Jones, C., A. Hazra, and L. M. Carvalho, 2015: The Madden-Julian Oscillation and boreal winter forecast skill: An analysis of NCEP CFSv2 reforecasts. J. Climate, 28, 6297-6307, https:// doi.org/10.1175/JCLI-D-15-0149.1.

Kedzierski, R. P., K. Matthes, and K. Bumke, 2016: The tropical tropopause inversion layer: Variability and modulation by equatorial waves. Atmos. Chem. Phys., 16, 11617-11633, https://doi.org/10.5194/acp-16-11617-2016.

Kerns, B. W., and S. S. Chen, 2016: Large-scale precipitation tracking and the MJO over the Maritime Continent and IndoPacific warm pool. J. Geophys. Res. Atmos., 121, 8755-8776, https://doi.org/10.1002/2015JD024661.

Kikuchi, K., B. Wang, and Y. Kajikawa, 2012: Bimodal representation of the tropical intraseasonal oscillation. Climate Dyn., 38, 1989-2000, https://doi.org/10.1007/s00382-011-1159-1.

Kiladis, G. N., J. Dias, K. H. Straub, M. C. Wheeler, S. N. Tulich, K. Kikuchi, K. M. Weickmann, and M. J. Ventrice, 2014: A comparison of OLR and circulation-based indices for tracking the MJO. Mon. Wea. Rev., 142, 1697-1715, https://doi.org/ 10.1175/MWR-D-13-00301.1.

Kousky, V. E., and R. W. Higgins, 2007: An alert classification system for monitoring and assessing the ENSO cycle. Wea. Forecasting, 22, 353-371, https://doi.org/10.1175/WAF987.1.

LaFleur, D. M., B. S. Barrett, and G. R. Henderson, 2015: Some climatological aspects of the Madden-Julian oscillation (MJO). J. Climate, 28, 6039-6053, https://doi.org/10.1175/ JCLI-D-14-00744.1.

Lawrence, D. M., and P. J. Webster, 2002: The boreal summer intraseasonal oscillation: Relationship between northward and eastward movement of convection. J. Atmos. Sci., 59, 1593-1606, https://doi.org/10.1175/1520-0469(2002)059<1593: TBSIOR $>2.0 . \mathrm{CO} ; 2$.

Lee, J. C. K., and N. P. Klingaman, 2018: The effect of the quasibiennial oscillation on the Madden-Julian oscillation in the Met Office Unified Model Global Ocean Mixed Layer configuration. Atmos. Sci. Lett., 19, e816, https://doi.org/10.1002/asl.816.

Lee, J. Y., B. Wang, M. C. Wheeler, X. Fu, D. E. Waliser, and I. S. Kang, 2013: Real-time multivariate indices for the boreal summer intraseasonal oscillation over the Asian summer monsoon region. Climate Dyn., 40, 493-509, https://doi.org/ 10.1007/s00382-012-1544-4.

Lindzen, R. S., and A. R. Holton, 1968: A theory of the Quasi-Biennial Oscillation. J. Atmos. Sci., 25, 1095-1107, https://doi.org/10.1175/ 1520-0469(1968)025<1095:ATOTQB > 2.0.CO;2.

Liu, C., B. Tian, K.-F. Li, G. L. Manney, N. J. Livesey, Y. L. Yung, and D. E. Waliser, 2014: Northern Hemisphere mid-winter 
vortex-displacement and vortex-split stratospheric sudden warmings: Influence of the Madden-Julian Oscillation and Quasi-Biennial Oscillation. J. Geophys. Res., 119, 12599 12 620, https://doi.org/10.1002/2014JD021876.

Madden, R. A., and P. R. Julian, 1971: Detection of a 40-50 day oscillation in the zonal wind in the tropical Pacific. J. Atmos. Sci., 28, 702-708, https://doi.org/10.1175/1520-0469(1971) 028<0702:DOADOI $>2.0 . \mathrm{CO} ; 2$.

—, and — 1972: Description of global-scale circulation cells in the tropics with a 40-50 day period. J. Atmos. Sci., 29, 1109-1123, https:// doi.org/10.1175/1520-0469(1972)029<1109:DOGSCC > 2.0.CO;2.

Marshall, A. G., H. H. Hendon, S. W. Son, and Y. Lim, 2017: Impact of the quasi-biennial oscillation on predictability of the Madden-Julian oscillation. Climate Dyn., 49, 1365-1377, https://doi.org/10.1007/s00382-016-3392-0.

McPhaden, M. J., X. Zhang, H. Hendon, and M. C. Wheeler, 2006: Large scale dynamics and MJO forcing of ENSO variability. Geophys. Res. Lett., 33, L16702, https://doi.org/10.1029/ 2006 GL026786.

Nishimoto, E., and S. Yoden, 2017: Influence of the stratospheric quasi-biennial oscillation on the Madden-Julian oscillation during austral summer. J. Atmos. Sci., 74, 1105-1125, https:// doi.org/10.1175/JAS-D-16-0205.1.

Peatman, S. C., A. J. Matthews, and D. P. Stevens, 2014: Propagation of the Madden-Julian Oscillation through the Maritime Continent and scale interaction with the diurnal cycle of precipitation. Quart. J. Roy. Meteor. Soc., 140, 814-825, https:// doi.org/10.1002/qj.2161.

Roundy, P. E., C. J. Schreck, and M. A. Janiga, 2009: Contributions of convectively coupled equatorial Rossby waves and Kelvin waves to the real-time multivariate MJO indices. Mon. Wea. Rev., 137, 469-478, https://doi.org/10.1175/2008MWR2595.1.

Son, S. W., Y. Lim, C. Yoo, H. Hendon, and J. Kim, 2017: Stratospheric control of the Madden-Julian oscillation. J. Climate, $\mathbf{3 0}$, 1909-1922, https://doi.org/10.1175/JCLI-D-16-0620.1.
Straub, K. H., 2013: MJO initiation in the real-time multivariate MJO index. J. Climate, 26, 1130-1151, https://doi.org/10.1175/ JCLI-D-12-00074.1.

Stull, R. B., 1995: Meteorology Today for Scientists and Engineers. West Pub., 385 pp.

Taguchi, M., 2010: Observed connection of the stratospheric quasibiennial oscillation with El Niño-Southern Oscillation in radiosonde data. J. Geophys. Res., 115, D18120, https://doi.org/ 10.1029/2010JD014325.

Tam, C. Y., and N. C. Lau, 2005: Modulation of the Madden-Julian Oscillation by ENSO: Inferences from observations and GCM simulations. J. Meteor. Soc. Japan, 83, 727-743, https://doi.org/ 10.2151/jmsj.83.727.

Wallace, J. M., R. L. Panetta, and J. Estberg, 1993: Representation of the equatorial stratospheric quasi-biennial oscillation in EOF phase space. J. Atmos. Sci., 50, 1751-1762, https://doi.org/ 10.1175/1520-0469(1993)050<1751:ROTESQ > 2.0.CO;2.

Wang, J., H. Kim, E. Chang, and S. Son, 2018: Modulation of the MJO and North Pacific storm track relationship by the QBO. J. Geophys. Res. Atmos., 123, 3976-3992, https://doi.org/ 10.1029/2017JD027977.

Wheeler, M., and H. Hendon, 2004: An all-season real-time multivariate MJO index: Development of an index for monitoring and prediction. Mon. Wea. Rev., 132, 1917-1932, https://doi.org/ 10.1175/1520-0493(2004)132<1917:AARMMI>2.0.CO;2.

Yoo, C., and S. W. Son, 2016: Modulation of the boreal wintertime Madden-Julian Oscillation by the stratospheric quasi-biennial oscillation. Geophys. Res. Lett., 43, 1392-1398, https://doi.org/ 10.1002/2016GL067762.

Zhang, C., and J. Ling, 2017: Barrier effect of the Indo-Pacific Maritime Continent on the MJO: Perspectives from tracking MJO precipitation. J. Climate, 30, 3439-3459, https://doi.org/ 10.1175/JCLI-D-16-0614.1.

— , and B. Zhang, 2018: QBO-MJO connection. J. Geophys. Res. Atmos., 123, 2957-2967, https://doi.org/10.1002/2017JD028171. 